\title{
Identification of Fall Risks by Nurses in Hospitalized Adult Patients
}

\section{Z. Slezakova (Zuzana Slezakova), J. Kristova (Jarmila Kristova), E. Miklovicova (Emilia Miklovicova), Z. Bachrata (Zuzana Bachrata)}

Slovak Medical University in Bratislava, Faculty of Nursing and Professional

Health Studies, Slovakia.

\section{E-mail address:}

zuzana.slezakova@szu.sk

\section{Reprint address:}

Zuzana Slezakova

Faculty of Nursing \& Professional Health Studies

Slovak Medical University in Bratislava

12 Limbova St.

83303 Bratislava

Slovakia

Source: Clinical Social Work and Health Intervention

Volume: 12

Issue: 3

Pages: $67-75$

Cited references: 28

\section{Reviewers:}

Steve Szydlowski

University of Scranton School of Education, USA.

Pawel S. Czarnecki

Rector of the Warsaw Management University, PL.

\section{Keywords:}

Fall. Fall Risk Factors. Nursing Practice.

\section{Publisher:}

International Society of Applied Preventive Medicine i-gap

CSWHI 2021; 12(3): 67 - 75; DOI: 10.22359/cswhi_12_3_12 (C) Clinical Social Work and Health Intervention

\section{Abstract:}

The aim of this study was to provide a nurses' comparison of fall risks in hospitalized adults according to gender, age and clinic, and to identify significant risk factors associated with the specific levels of the risk of falling. The respondent group consisted of patients hospitalized in selected hospital wards. Morse Fall Scale was used to map the data. We tested the statistical significance of differences among categories by using the chí 2 test, Mann-Whitney U test and Kruskal-Wallis test. The average risk score of falling in a group of 688 patients was at a high level $47.87 \pm 26.4$. In the group of 430 elderly patients, we found significantly higher average values than in the group of 258 patients younger than 65 years $(\mathrm{p}=<0.00001)$. 
Patients hospitalized in the geriatric ward had the highest average Morse Fall Scale values $(55.3 \pm 26.11)$. The results of our study confirmed the risk of falling in selected groups of patients.

\section{Introduction}

Falls of hospitalized adult patients belong to undesirable events in the nursing practice. Despite the frequent occurrence of this phenomenon, there is no generally accepted definition of the term "fall" (Zecevic, Salmoni, Speechley \& Vandervoort, 2006; Schwenk et al., 2012; Masud \& Morris, 2001). Definitions are variable, but essentially, they have the same characteristics. Morris \& Isaacs (1980) published a definition of a fall as an undesirable event in which a patient unexpectedly falls to the ground. Later, more definitions were added to the timeline. Specialists and professional organizations usually define a fall as an unintentional, unpredictable and sudden fall of a patient to the floor, lower area or on another object (person, item, furniture, staircase, etc.) without or with injury (World Health Organization [WHO], 2007; Miertova, Borikova, Tomagova, \& Ziakova, 2018; National Health Service [NHS], 2015). The Agency for Healthcare Research and Quality (AHRQ, 2013) informs that falls in hospitals occur without any assistance and are caused by physiological (e.g. faints) or environmental (e.g. slippery floor) reasons. Nowadays, both historically older and newer data on the monitoring of falls in hospitalized patients are available. For example, the Czech Association of Nurses (CAS, 2012) provides statistics from the Czech Republic which shows that 7,660 out of 755,498 hospitalized patients at 38 medical facilities fell. In 2015 , the medical staff reported 4,325 falls out of 524,870 registered hospitalized patients from 19 hospitals in the Czech Republic. According to NHS documentation (2017), falls were reported in 247,000 patients $(57,000$ in patients under 65 years of age and 190,000 in patients older than 65 years) in England in 2015/2016. AHRQ (2013) estimates that from 700,000 up to 1 million hospitalized patients fall in the US each year. In the Slovak Republic, there are data on falls in hospitalized patients available from 2013. Health Care Surveillance Authority of the Slovak Republic in the last published Activity Report (UDZS SR, 2013) lists 3,075 falls and injuries of patients that occurred at 65 institutional medical facilities in the Slovak Republic. Based on the above-mentioned WHO data (2007), the Global Report on Falls Prevention in Older Age (2007) associates the increasing tendency for hospitalized patients to fall with the global population aging. A $100 \%$ increase of patient falls is estimated in 2030. Falls of hospitalized patients cannot be fully prevented, although there are possibilities and recommendations for their elimination. The first step in eliminating falls in a hospital setting is to identify the at-risk patients (Stevens, 2005). Nursing practice currently has a number of standardized simplex and multidimensional measuring tools for such detection. Most often they contain a combination of several subjective risk factors: age; physical, mental and environmental risk factors; risk factors of pharmacotherapy; etc. (e.g. Assessment of High Risk to Fall; Downton Fall Risk Index; Fall Assessment Questionnaire; Falls Screening Tools; Falls Risk for Hospitalized Older People; Hendrich Fall Risk Model; Morse Fall Scale; Patient Fall Questionnaire; etc.). The most frequently used ones in nursing practice are; Morse Fall Scale; Hendrich Fall Risk Model; St. Tomas Risk Assessment Tool in Falling Elderly Inpatients in patients older than 65 years (Borikova, Tomagova, $\&$ Miertova, 2018). The choice of an adequate measuring tool depends on: the patient's age; current health status; other situational factors. Despite the fact that there are currently enough standardized tools, nursing in the Slovak Republic hasn't developed a unified standardized procedure for detecting risk factors in hospitalized patients that nurses would use in nursing practice.

\section{Settings and Methods}

The main goal of the presented research was to determine the fall risk degree by screening when using the Morse Fall Scale (MFS-CZ), compare fall risks according to: gender; age and ward; analyse the individual fall risk factors in hospitalized patients and identify the significant risk factors associated with different levels of fall risk. 
Protocols, which were a part of the medical documentation, were used to process the defined goal. The protocol contained items focused on respondents' identification data (gender, age, hospital ward) and MFS-CZ. MFS-CZ focused on assessing 6 significant risk factors: history of falls; secondary diagnosis; walking aid; intravenous cannula/therapy; gait; mental condition. The patient could have obtained $0-30$ points (a range of 0-125 points) in each risk factor. Based on the final score for six risk factors the patient was assigned to a group with no fall risk (0 points), low fall risk ( $<25$ points), moderate fall risk (25-45 points) and high fall risk ( $>45$ points) (Morse et al., 1989; Miertova, 2019).

The respondent sample consisted of 688 respondents. Their inclusion in the sample was conditioned by their age - they had to be at least 18 years old, indication for hospitalization in the medical, surgical or geriatric department and an assessment of the fall risk within 24 hours of their admission. $426(61.92 \%)$ women and 262 $(38.03 \%)$ men participated in the survey. The average age of respondents was 67.16 years, with a range of 19-97 years (median $71, \mathrm{SD} \pm 18.54$ ). $348(50.58 \%)$ patients hospitalized in medical departments, 142 (20.64\%) patients hospitalized in surgical units and 198 (28.78\%) patients hospitalized in geriatric wards took part in the study.

We used descriptive statistics to interpret the results. The statistical significance of differences among categories was tested by chí ${ }^{2}$ test. Differences between two selected averages of the independent samples were evaluated, due to the asymmetry of distribution of each variable in observed samples by non-parametric tests for two independent samples (Mann-Whitney U test), or three independent samples (Kruskal-Wallis test). The correlation between variables was assessed by the Spearman's rank correlation coefficient. We presented mainly significant results with differences at $\mathrm{p}<0.05$.

\section{Results and discussion}

In a group of 688 patients, the average score of fall risk according to MFS was at a high risk level $47.87 \pm 26.4$ (minimum 0 , maximum 125 ) . After classifying patients into four basic levels of fall risk according to their final score, we found that: 336 patients $(48.84 \%)$ were at a high fall risk; 222 patients $(32.27 \%)$ were at a moderate fall risk; 82 survey participants $(11.92 \%)$ were at a low fall risk; only 48 probands $(6.98 \%)$ did not confirm the MFS risk of a fall.

\section{Level of fall risk according to selected demographic indicators}

When comparing the MFS results according to demographic indicators (age, gender and hospital ward), we found out that the age of patients correlated moderately with the overall score achieved by MFS $\left(\mathrm{r}_{\mathrm{S}}=0.51, \mathrm{p}=<0.00001\right)$. Values of the overall MFS score were getting higher along with the increasing age of respondents. Table 1 shows the basic descriptive characteristics of the overall MFS score according to age, gender and hospital ward.

Based on the knowledge that multiple risk factors increase the fall risk in seniors, we directed our attention on differences in the overall MFS score in patients under and over 65 years of age. In the group of 430 elderly patients we found

TABLE 1 Descriptive characteristics of the MFS score by age, gender and hospitalization

\begin{tabular}{|l|l|r|r|r|r|rrr|}
\hline \multirow{2}{*}{ Variables } & \multirow{2}{*}{ Categories } & \multirow{2}{*}{ Mean } & \multirow{2}{*}{ SD } & \multirow{2}{*}{ Min. } & \multirow{2}{*}{ Max. } & \multicolumn{3}{|c|}{ Risk of falls (\%) } \\
\cline { 6 - 9 } & & & & & & Low & Moderate & High \\
\hline \multirow{2}{*}{ Gender } & $<65$ years & 31,51 & 23,13 & 0 & 85 & 22,48 & 37,21 & 22,48 \\
& $\geq 65$ years & 57,69 & 23,23 & 0 & 125 & 5,58 & 29,3 & 64,65 \\
& Male & 49,77 & 23,89 & 0 & 105 & 10,69 & 35,11 & 51,15 \\
& Female & 46,71 & 27,83 & 0 & 125 & 12,68 & 30,52 & 47,42 \\
\hline \multirow{2}{*}{ Ward type } & Medical & 44,74 & 28,03 & 0 & 100 & 9,2 & 31,61 & 45,98 \\
& Surgical & 45,21 & 20,27 & 0 & 95 & 19,72 & 36,62 & 42,25 \\
& Geriatric & 55,03 & 26,11 & 15 & 125 & 11,11 & 30,3 & 58,59 \\
\hline
\end{tabular}

SD: standard deviation

Min.: minimum score

Max.: maximum score 
significantly higher average MFS values than in the group of 258 younger patients $(p=<0.0001)$. According to MFS, the average score of the fall risk of respondents younger than 65 years was at a moderate risk level $31.51 \pm 23.13$, while the average score of the fall risk of patients in the age of 65 and older was at a high risk level $57.69 \pm$ 23.23. Similarly, when we classified both groups of patients into the four basic levels of fall risk, we noticed that more patients at a high risk of falling are in the $65+$ age category $(64.65 \%)$ than in the group of respondents younger than 65 years $(22.48 \%)$. We also found that the classification of survey participants according to the overall MFS score was the same for men and

FIGURE 1 Levels of risk of falls by gender and age
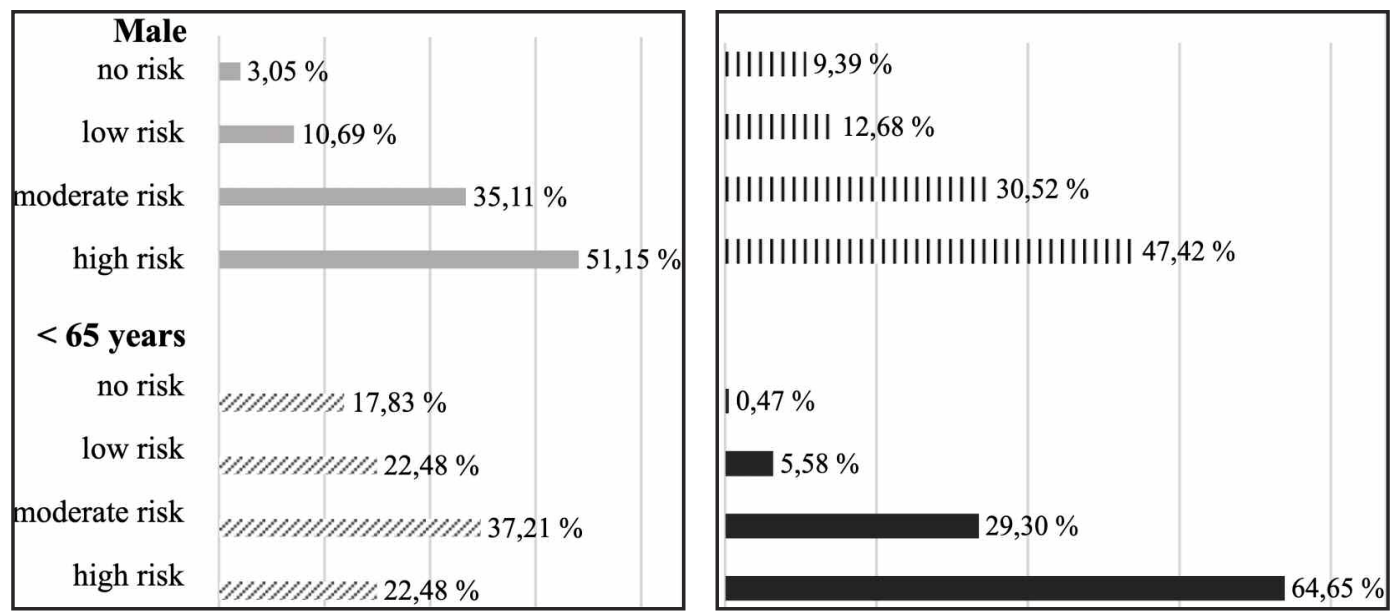

FIGURE 2 Levels of risk of falls by hospitalization

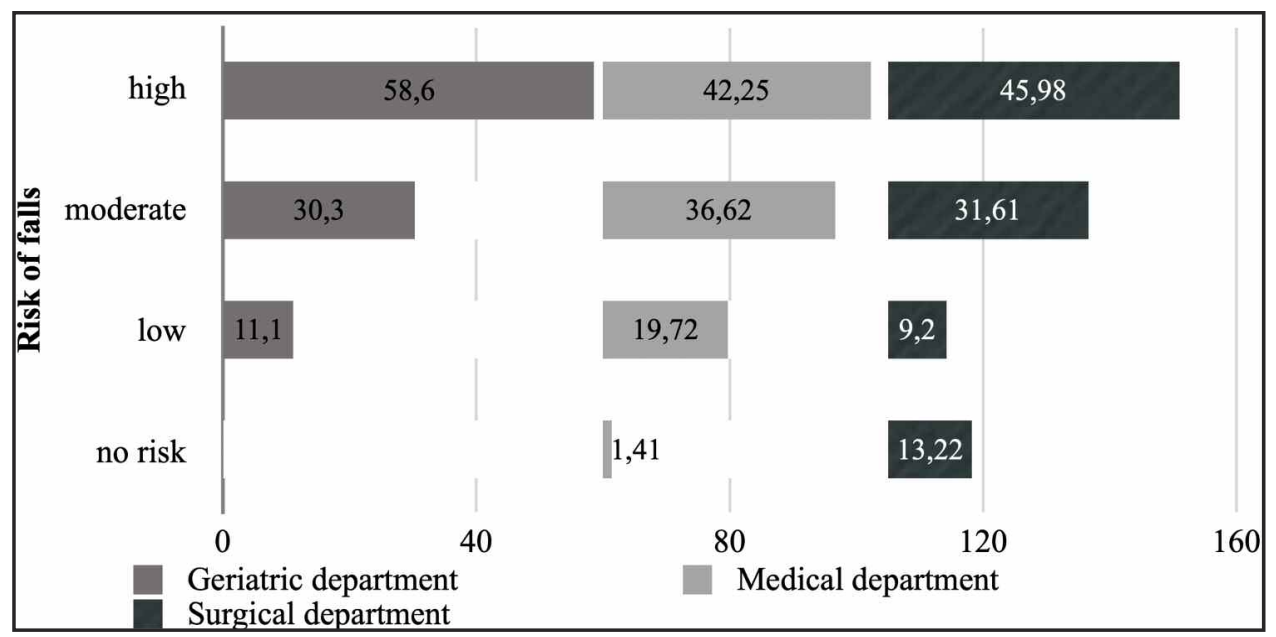


est average MFS values were achieved by patients hospitalized in the geriatric units $(55.3 \pm$ 26.11) and the lowest average MFS values were achieved by patients hospitalized in the medical departments (44.74 \pm 28.03$)$. Patients hospitalized in the surgical department achieved an average MFS value 45.21 \pm 20.27 ; high fall risk was observed in $58.59 \%$ patients hospitalized in geriatric wards; $45.98 \%$ patients hospitalized in medical units; $42.25 \%$ patients hospitalized in surgical departments. Distribution of respondents into four levels of fall risk according to MFS by a hospital ward is presented in Chart 2.

\section{Analysis of fall risk factors}

We also analysed the presence of six risk factors: a history of falls; secondary diagnoses; walking aid; intravenous cannula/therapy; gait abnormality; mental disorders. In the surveyed group of patients, the most common risk factors were: a secondary diagnosis $(75.58 \%)$; intravenous cannula/therapy (52.91\%); history of falls $(45.91 \%)$. We noticed a less frequent occurrence of the following risk factors: gait abnormality $(42.44 \%)$; use of a walking aid $(38.66 \%)$; altered mental status $(18.31 \%)$. Table 2 shows the presence of risk factors in the whole sample by gender, age and hospital department.

When comparing the presence of fall risk factors by patients' gender, analysis confirmed a statistically significantly higher occurrence of intra- venous therapy/cannula in men than in women ( $\mathrm{p}$ $<0.0001)$. Other fall risk factors were equally represented in both genders. In the group of patients in the 65+ age category, we noticed a significantly higher incidence of all risk factors ( $p$ $<0.0001)$ than in younger patients. The only exception was a presence of intravenous therapy/cannula which was not affected by age $(p=0.114)$.

Similar statistically significant differences were noted in the assessment of fall risk factors according to the hospital wards. Patients hospitalized in surgical departments reported a significantly more frequent presence of intravenous therapy/cannula ( $p<0.0001)$. In the group of patients hospitalized in medical departments there were many more patients with the risk factor history of falls $(p=0.003)$. Among the significant predictors of a fall of patients in the geriatric units were secondary diagnosis ( $p<0.0001)$, the use of a walking aid ( $p<0.0001)$, gait abnormality $(\mathrm{p}=0.003)$ and mental disorder $(\mathrm{p}<0.0001)$.

\section{Relation among risk factors and the level of fall risk}

With the focus on the last objective of the research study, we found out which risk factors have a significantly positive correlation $\left(r_{s} \geq 0.3\right)$ with the individual levels of fall risk. (Table 3).

The risk factor intravenous therapy/cannula $\left(r_{s} 0.878, \mathrm{p}<0.0001\right)$ correlated significantly pos-

TABLE 2 Distribution of risk factors by gender, age and hospital department

\begin{tabular}{|l|c|c|c|c|c|c|c|c|c|c|}
\hline & \multicolumn{3}{|c|}{ Gender } & \multicolumn{3}{c|}{ Age } & \multicolumn{3}{c|}{ Ward type } \\
\hline $\begin{array}{l}\text { Risk } \\
\text { factors }\end{array}$ & Men & Women & $p$ & $\begin{array}{c}<65 \\
\text { years }\end{array}$ & $\begin{array}{c}\geq 65 \\
\text { years }\end{array}$ & $p$ & GER & SUR & MED & $p$ \\
\hline $\begin{array}{l}\text { History } \\
\text { of falls }\end{array}$ & 48.09 & 44.6 & 0.415 & 27.91 & 56.74 & $<0.0001$ & 46.46 & 33.8 & 50.57 & $\mathbf{0 . 0 0 3}$ \\
\hline $\begin{array}{l}\text { Secondary } \\
\text { diagnosis }\end{array}$ & 77.86 & 74.18 & 0.316 & 43.41 & 94.88 & $<0.0001$ & 98.99 & 63.38 & 67.24 & $<0.0001$ \\
\hline Walking aid & 35.11 & 40.85 & 0.156 & 26.36 & 46.05 & $<0.0001$ & 57.58 & 29.58 & 31.61 & $<0.0001$ \\
\hline IV therapy & 62.6 & 46.95 & $<0.0001$ & 48.84 & 55.35 & $\mathbf{0 . 1 1 4}$ & 37.37 & 90.14 & 46.55 & $<0.0001$ \\
\hline $\begin{array}{l}\text { Gait } \\
\text { abnormality }\end{array}$ & 36.69 & 44.13 & 0.354 & 27.13 & 51.63 & $<0.0001$ & 49.49 & 28.17 & 44.25 & $\mathbf{0 . 0 0 3}$ \\
\hline $\begin{array}{l}\text { Altered } \\
\text { mental status }\end{array}$ & 15.27 & 20.19 & 0.128 & 5.43 & 26.05 & $<0.0001$ & 31.31 & 9.86 & 14.37 & $<0.0001$ \\
\hline
\end{tabular}

GER: geriatric department, SUR: surgical department, MED: medical department

$\mathrm{p}$ : level of statistical significance for the chí ${ }^{2}$ test 
TABLE 3 Relation among risk factors and the level of fall risk

\begin{tabular}{|l|c|c|c|c|c|c|}
\hline \multirow{2}{*}{ Risk factors } & \multicolumn{6}{c|}{ Risk of falls } \\
\cline { 2 - 7 } & \multicolumn{2}{|c|}{ Low } & \multicolumn{2}{c|}{ Moderate } & \multicolumn{2}{c|}{ High } \\
\cline { 2 - 7 } & $r_{S}$ & $p$ & $r_{S}$ & $p$ & $r_{s}$ & $p$ \\
\hline History of falls & 0.156 & 0.327 & $\mathbf{0 . 3 2 6}$ & $\mathbf{0 . 0 0 0 4}$ & $\mathbf{0 . 3 0 0}$ & $<0.0001$ \\
\hline Secondary diagnosis & -0.676 & 0.000 & 0.291 & 0.001 & 0.184 & 0.017 \\
\hline Walking aid & 0.156 & 0.327 & 0.060 & 0.523 & $\mathbf{0 . 3 4 1}$ & $<0.0001$ \\
\hline IV therapy & $\mathbf{0 . 8 7 8}$ & $<0.0001$ & 0.126 & 0.184 & 0.241 & 0.001 \\
\hline Gait abnormality & -0.504 & 0.000 & -0.153 & 0.106 & $\mathbf{0 . 4 0 3}$ & $<0.0001$ \\
\hline Altered mental status & -0.127 & 0.428 & -0.145 & 0.124 & 0.263 & 0.0005 \\
\hline
\end{tabular}

$p$-level of statistical significance; $r_{s}-$ Spearman's rank correlation coefficient

itively in the first group of patients at a low fall risk. In the second group of patients, a moderate positive correlation between the risk factor history of falls and a moderate fall risk $\left(r_{S} 0.326, \mathrm{p}\right.$ $=0.0004$ ) was confirmed. In the sample of patients at a high fall risk, statistically significant moderate correlations were observed among gait abnormalities $\left(r_{s}=0.403, \mathrm{p}<0.0001\right)$, the use of walking aids $\left(r_{S}=0.341, \mathrm{p}<0.0001\right)$, history of falls $\left(r_{s}=0.3, \mathrm{p}<0.0001\right)$ and a high fall risk.

Nowadays, patient safety is a priority of nursing care. Falls of hospitalized patients make: their treatment complicated; have serious physical, mental and social consequences; increase economic costs of health care; bring a risk of legal actions against medical facilities for failing to provide a proper and safe health care. The identification of fall risks is necessary to increase safety of patients during hospitalization. Using the standardized measuring tools to assess the risk of a fall is valuable and practical strategy that nurses can use.

By performing a fall risk screening using the MFS tool, we were trying to find the level of fall risk and the presence of individual risk factors for falls in the selected group of hospitalized patients. In the respondent group of patients hospitalized in medical, surgical and geriatric departments, we discovered that the average MFS value was at the high risk level $(47.87 \pm 26.4)$. Previous studies oriented to this particular topic have produced diverse data. Miertova, et al . (2018) reported an average fall risk $45.7 \pm 20.2$ in 103 patients hospitalized in the neurology department, which also corresponded to the high risk.
A higher average MFS score (57.2) counting among the high fall risks was also reported by Forrest, Chen, Huss \& Giesler (2013) in patients requiring institutional rehabilitation, most of whom had abnormal gait.

McGibbon et al. (2019) analysed the risk of a fall in 888 Canadian chronic patients and found that their average MFS score was $58.76 \pm 25.49$. In the process of a patient classification by MFS, our study confirmed a high fall risk in $48.84 \%$ patients, a moderate risk in $32.27 \%$ patients and a low risk in $11.92 \%$ patients. Similar results were presented in a long-term study in 1,487 adult patients in Brazil - a high fall risk was confirmed in $40.1 \%$ respondents, a moderate risk in $34.2 \%$ survey participants and a low risk in 25.7\% patients (Urbanetto et al., 2016; Pasa et al., 2017). When monitoring 831 patients hospitalized in the university hospital, they identified a high risk fall in $36.6 \%$ hospitalized patients. The variability of research outcomes emphasizes the fact that both the average MFS score and the degree of fall risk are greatly influenced by the profile of patients enrolled in the study and the nature of health care provided.

By analysing MFS results by age, gender and hospital ward, we found a statistically significantly higher score in patients in the age of 65 and older $(57.69 \pm 23.23)$ than in patients younger than 65 years $(31.51 \pm 23.13)$. We did not notice any differences in score based on gender. A higher occurrence of the high risk fall in older patients was also confirmed by Miertova et al. (2018), Sardo, Simões, Alvarelhão, \& Simões (2016), Bittencourt et al. (2017). The association 
of higher age with the high risk fall is also documented by the highest average MFS score measured in our study in patients hospitalized in the geriatric unit $(55.3 \pm 26.11)$, as well as the identification of $58.59 \%$ seniors at high risk of a fall. It is evident that as age increases, the risk factors contributing to the fall risk are accumulating. This was also confirmed by many other different studies (Urbanetto et al., 2016; Simpson, Rosenthal, Cumbler \& Likosky, 2013).

Compared to the results of our empirical research, other authors confirmed the relation between the level of fall risk and patients' gender: Sardo et al. (2016) confirmed a higher fall risk in women \& McGibbon et al. (2019), on the other hand, a higher probability to fall in men. According to Bittencourt et al. (2017) \& Falcão et al. (2019), there is no connection between the fall risk and gender.

By analysing the obtained data, we found that the level of fall risk of the surveyed group is mostly affected by: risk factors; secondary diagnosis which was observed in $75.58 \%$ patients; intravenous therapy/cannula observed in $52.91 \%$ patients and history of falls observed in $45.91 \%$ patients. Pasa et al. (2017) in their research also confirmed the highest prevalence of these two risk factors: intravenous cannula in $92.8 \%$ patients and secondary diagnosis in $60.9 \%$ observed research participants. Rocha et al. (2013) obtained similar results in the probe. They proved the positive correlation between the fall risk and intravenous cannula (83.3\%). De Albuquerque et al. (2013) also confirmed the secondary diagnosis as the most frequent fall risk factor. The study further discovered a presence of several risk factors in the sample of patients in the 65+ age group, which may predispose them to a fall or injury. Based on the results, we can conclude that causes of the increased fall risk in seniors are multifactorial. Among the significant predictors of falls in the group of patients at high risk of a fall was gait abnormality, the use of a walking aid and history of falls.

Based on the results of the research findings, the following recommendations for the nursing practice in the Slovak Republic were formulated: - carry out a research on the national level to obtain a comprehensive picture of the observed reality,
- strengthen the education of nurses in standardized measuring tools for detecting fall risk factors in hospitalized patients,

- consistently implement a multifactorial assessment followed by multifactorial interventions (National Institute for Health and Care Excellence [NICE], 2013) in practice,

- implement the complex training program Fallproof $(\mathrm{C}$ (WHO, 2007) for medical staff to acquire and use skills for reducing the fall risk in elderly adults,

- strengthen the educational interventions of nurses aimed at patients at risk of a fall - promoting safe mobility.

\section{Conclusions}

The results of our study confirmed that out of the total 688 research participants, 336 patients $(48.84 \%)$ were at high risk of a fall and 222 $(32.27 \%)$ were at moderate risk of a fall. The prevention of fall risks represents an essential element of nursing care for hospitalized patients prone to falls. This is possible on condition that: a thorough multifactorial assessment of a specific patient is conducted; followed by an implementation of effective interventions; a high-quality cooperation between doctors and nurses.

\section{References}

1. AGENCY FOR HEALTHCARE RESEARCH AND QUALITY (2013) Preventing falls in hospitals. A toolkit for improving quality of care. Retrieved from: http://www. ahrq.gov/sites/default/files/publications/files/ fallpxtoolkit.pdf.

2. BITTENCOURT V L L, GRAUBE S L, STUMM E M F, BATTISTI I D E, LORO M M, WINKELMANN E R (2017) Factors associated with the risk of falls in hospitalized adult patients. Revista da Escola de Enfermagem da USP, 51. doi: 10.1590/S1980$220 X 2016037403237$.

3. BORIKOVA I, TOMAGOVA M, MIERTOVA M (2018) Falls and their prevention in hospitalized patients. Martin: Osveta.

4. CZECH ASSOCIATION OF NURSES (2013) Monitoring of falls in hospitalized patients in 2011-2012. Retrieved from: http:// www.cnna.cz/docs/tiskoviny/zaverecna_ zprava_2011_2012-91b6f.pdf.

5. DA ROCHA H B, SAMUEL R D C F, 
LAHTI L A, DE AZEVEDO R C, CREUTZBERG M,URBANETTO J S (2013) Assessment of the risk of stays in hospitalized adults according to the Morse Fall Scale translated into Portuguese. Revista da Graduação, 6(1). Retrieved from:http://revistaseletronicas.pucrs.br/ojs/index.php/graduacao/a rticle/view/13763.

6. DE ALBUQUERQUE N L S, DE ASSIS SISNANDO M J, SAMPAIO FILHO S P C, MORAIS H C C, DE OLIVEIRA LOPES M V, DE ARAUJO T L (2013) Risk factors for stays in hospitalized patients with ischemic heart disease. Revista da Rede de Enfermagem do Nordeste, 14(1), pp. 158-168. Retrieved from: https://www.redalyc.org/pdf/ 3240/324027985018.pdf.

7. FALCAO R M D M, COSTA K N D F M, FERNANDES M D G M, PONTES M D L D F, VASCONCELOS J D M B, OLIVEIRA J D S (2019) Risk of falls in hospitalized elderly people. Revista gaúcha de enfermagem, 40(esp). doi.org/10.1590/1983-1447.2019. 20180266.

8. FORREST G P, CHEN E, HUSS S, GIESLER A A (2013) Comparison of the functional independence measure and Morse fall scale as tools to assess risk of fall on an inpatient rehabilitation. Rehabilitation nursing, 38(4), pp. 186-192. doi: 10.1002/rnj.86. Epub 2013 May 29.

9. MCGIBBON C A, SLAYTER J T, YETMAN L, MCCOLLUM A, MCCLOSKEY R, GIONET S G, OAKLEY H, JARRETT P (2019) An Analysis of Falls and Those who Fall in a Chronic Care Facility. Journal of the American Medical Directors Association, 20(2), pp. 171-176. doi: 10.1016/j.jamda. 2018.06.022. Epub 2018 Aug 11.

10. MASUD T, MORRIS R O (2001) Epidemiology of falls. Age Ageing, 30(4) , 3-7. doi:10.1093/ageing/30.suppl_4.3.

11. MIERTOVA M (2019) Fall risk in nursing practice in hospitalized patients with neurological disease. Praha: Grada.

12. MIERTOVA M, BORIKOVA I, TOMAGOVA M, ZIAKOVA K (2018) Risk factors of falling in patients with neurological diseases. Kontakt, 20(3), pp. 234-240. doi: 10.1016/j.kontakt.2018.07.002.

13. MORRIS E V, ISAACS B (1980) The pre- vention of falls in geriatric hospital. Age and Ageing, 9(3), 1981-1985. Retrieved from: http://www.ncbi.nlm.nih.gov/pubmed/74572 74.

14. MORSE J M, MORSE R M, TYLKO S J (1989) Development of a scale to identify the fall-prone patient. Canadian Journal on Aging, 8(4), 366-377. doi.org/10.1017/ S0714980800008576.

15. NASSAR N, HELOU N, MADI C (2014) Predicting falls using two instruments (the Hendrich Fall Risk Model and the Morse Fall Scale) in an acute care setting in Lebanon. Journal of clinical nursing, 23(11-12), pp. 1620- 629. doi: 10.1111/jocn.12278. Epub 2013 Oct 11.

16. NATIONAL HEALTH SERVICE. (2015) Slips, Trips and Falls (Inpatients) Policy. Ratified by: Safety and Risk Committee: 18th February 2015. Retrieved from: http://www. rdehospital.nhs.uk/docs/trust/foi/foi_responses/2015/september/Slips_Trips_andFalls.pdf.

17. NATIONAL HEALTH SERVICE (2017) The incidence and costs of inpatient falls in hospitals. Retrieved from: https://improvement. nhs.uk/documents/1471/Falls_report_July20 17.v2.pdf.

18. NATIONAL INSTITUTE FOR HEALTH AND CARE EXCELLENCE (2013) Falls Assessment and prevention of falls in older people. Retrieved from: http://www.nice. org.uk/guidance/cg161/evidence/falls-fullguidance-190033741.

19. PASA T S, MAGNAGO T S, URBANETTO J D S, BARATTO M A M, MORAIS B X, CAROLLO J B (2017) Risk assessment and incidence of falls in adult hospitalized patients. Revista Latino-Americana de Enfermagem, 25:e2862. doi.org/10.1590/15188345.1551.2862.

20. SARDO P M G, SIMÕES C S O, ALVARELHÃO J J M, SIMÕES J F F L (2016) Fall risk assessment: retrospective analysis of Morse Fall Scale scores in Portuguese hospitalized adult patients. Applied Nursing Research, 31, pp. 34-40. doi: 10.1016/j.apnr. 2015.11.013.

21. SIMPSON J R, ROSENTHAL L D, CUMBLER E U, LIKOSKY D J (2013) Inpatient falls: defining the problem and identifying possible solutions. Part I: an evidence-based 
review. Neurohospitalist, 3(3), pp. 135-143. doi: 10.1177/1941874412470665.

22. SCHWENK M, LAUENROTH A, STOCK C, MORENO R R, OSTER P, MCHUGH G, HAUER K (2012) Definitions and methods of measuring and reporting on injurious falls in randomised controlled fall prevention trials: a systematic review. Medical Research Methodology, 1-14. doi: 10.1186/1471-228812-50.

23. STEVENS J A (2005) Falls among older adults - risk factors and prevention strategies. Journal of Safety Research, 36(4) , 409-411. doi: 10.1016/j.jsr.2005.08.001.

24. THOMAS D, PAVIC A, BISACCIA E, GROTTS J (2016) Validation of fall risk assessment specific to the inpatient rehabilitation facility setting. Rehabilitation nursing, 41(5) , 253-259. doi: 10.1002/rnj.211.

25. HEALTH CARE SURVEILLANCE AUTHORITY OF THE SLOVAK REPUBLIC. (2013). Activity and management report 2012 of the Health Care Surveillance Authority. Retrieved from: http://www.udzssk.sk/documents/14214/19136/VE_7_Spr\%C3\%A1va+ o+\%C4\%8Dinnosti+a+hospod\%C3\%A1ren $\% \mathrm{C} 3 \% \mathrm{AD}+\% \mathrm{C} 3 \% \mathrm{BAradu}$ final.pdf/85d7b7 cd-8cc6-40de-af5a-d50116263b33.

26. URBANETTO J D S, PASA T S, BITTENCOUT H R, FRANZ F, ROSA V P P, MAGNAGO T S (2016) Analysis of risk prediction capability and validity of Morse Fall Scale Brazilian version. Revista gaucha de enfermagem 37(4), e62200. doi: 10.1590/19831447.2016.04.62200.

27. WORLD HEALTH ORGANIZATION (2007) Global Report on Falls Prevention in Older Age 2007. Retrieved from: http:// www.who.int/ageing/publications/Falls_prevention7March.pdf.

28. ZECEVIC A A, SALMONI A W, SPEECHLEY M, VANDERVOORT A A (2006) Defining a Fall and Reasons for Falling: Comparisons Among the Views of Seniors, Health Care Providers, and the Research Literature. The Gerontologist, 46(3), 367-376. doi.org/10.1093/geront/46.3.367. 